\title{
Cioran, el escepticismo y la elección estilística*
}

\author{
Cioran, skepticism and style election
}

\author{
Alfredo Abad \\ G.I. Filosofía y escepticismo \\ Escuela de Filosofía \\ Universidad Tecnológica de Pereira \\ E.mail: alfredoabad@utp.edu.co \\ ORCID: 0000-0002-7278-5797
}

Fecha de recepción: 12 de noviembre de 2018 Fecha de aprobación: 22 de febrero de 2019

Doi: 10.17533/10.17533/udea.ef.n60a11

Resumen. Cioran introduce en su obra dos elecciones estilisticas bastante claras. Una enfocada en el lirismo donde la poesía tiene una influencia muy amplia, y otra centrada en un lenguaje crítico guiado por una prosa ácida en donde el filósofo intenta desvincularse de los rastros líricos y poéticos. El artículo explora estas dos vertientes, señala sus particularidades, sus posibles antagonismos y las razones que motivan su uso en la obra del autor rumano a través de su impronta escéptica.

Palabras clave: escepticismo, estilo, poesía, lírica

Abstract. Cioran introduces two fairly clear stylistic choices in his work. One focused on lyricism where poetry has a very broad influence, and another focused on a critical language where he tries to detach himself from lyrical and poetic traces. The paper explores these two aspects and points out their particularities, their possible antagonisms and the reasons that motivate their use in the work of the Romanian author through its skeptical imprint.

Key words: skepticism, style, poetry, lyricism

¿Es posible pensar la filosofía al margen de un estilo? Es bien sabido para los lectores cioranianos que la pregunta debe tener una respuesta negativa, pues no fueron pocas las apreciaciones del autor rumano en torno al asunto; no en vano, fue para él una cuestión decisiva. Uno de los núcleos fundantes de la obra cioraniana está constituido por los énfasis circunscritos a la definición de un esteticismo, de

* El artículo hace parte del trabajo realizado dentro del grupo de investigación Filosofía y escepticismo de la Universidad Tecnológica de Pereira.

Cómo citar este artículo:

MLA: Abad, Alfredo. "Cioran, el escepticismo y la elección estilística". Estudios de Filosofía 60 (2019): 217-237.

APA: Abad, A. (2019). Cioran, el escepticismo y la elección estilística. Estudios de Filosofia, 60, 217-237.

Chicago: Alfredo Abad. "Cioran, el escepticismo y la elección estilística". Estudios de Filosofia n. ${ }^{\circ} 60$ (2019): 217-237.

Estud.filos $\mathrm{n}^{\circ}$ 60. Julio-diciembre de 2019. Universidad de Antioquia. pp. 217-237.

ISSN 0121-3628. ISSN-e 2256-358X 
una estilística que no necesariamente hay que asumir como mero adorno alrededor de un pensamiento. La preocupación que Cioran revela por este asunto no está circunscrita solamente al trabajo dispendioso que ocupó la redacción de sus obras. El referente más destacado al respecto es la composición de su Breviario de podredumbre (Précis de décomposition) auténtico referente del escepticismo contemporáneo, el cual fue reescrito varias veces como muestra de la exigencia estilística que demandaba el interés del autor, así como el perfeccionamiento del francés como lengua adoptada. Sin embargo, este trabajo denodado en el ámbito práctico está respaldado también por la exposición teórica que implica su concepción de la relación entre pensamiento, escepticismo y estilo.

De ninguna manera se trata de un esbozo menor, de una alusión intrascendente. De hecho, tal como se acaba de especificar, la obra cioraniana está marcada por una voluntad de estilo que no puede ignorarse si se intenta destacar una de las mejores prosas del pasado siglo. Pero por supuesto, no se trata simplemente de una actividad literaria, sino de una especificidad filosófica que Cioran mismo destacó en algunos escritos en los cuales perfiló una meditación sobre el estilo y el lenguaje. El rechazo de la oscuridad y de los fárragos filosóficos que tanta molestia le generaron, revela una muy distintiva concepción al respecto. La percepción que Cioran consigna con respecto al uso - o el abuso - de un lenguaje altamente difuso, lleno de divagaciones, equívoco, cargado de neologismos y sobre todo oscuro, destaca la importancia de lo que para él es un estilo claro y preciso. Las objeciones de Cioran para con una filosofía que se destaque por su carácter confuso no obedecen simplemente a un capricho estilístico, a una exigencia gramatical o un simple purismo en las formas. Al contrario, todo esto implica un sentido de lo que un pensamiento filosófico puede expresar, vincular, fundamentar.

\section{Filosofía y estilo}

El abierto rechazo que Cioran manifiesta con la escritura heideggeriana es uno de los ejemplos a partir de los cuales puede esclarecerse su pensamiento en lo que respecta al lenguaje. Lo destacable aquí es cómo a través de esta crítica, Cioran no descompone el pensamiento y el estilo sino que conjuga ambos en una asociación indistinguible. De hecho, uno de los aspectos resaltables es que a partir de sus ataques, tal como se expondrá más abajo, Cioran resalta su propia percepción de lo que es la filosofía. 
Heidegger y Céline — dos esclavos de su lenguaje, al punto de que para ellos liberarse de él equivaldría a desaparecer. Esclavizarse a su propia manera, allí se revela la necesidad de juego y de impostura. ¿Cómo desenmarañar la parte de cada uno de estos elementos? Sólo queda como fenómeno primordial la necesidad. Es lo que absuelve a maniacos del lenguaje (Cioran, 1997, p. 216). ${ }^{1}$

Revelador pasaje en tanto consigna puntualmente la falta que ve Cioran cuando la escritura se convierte en una impostura. El hecho de considerarla así, como un medio de encubrimiento, de necesidad maniaca anclada a un afán imprescindible por estremecer y corromper el lenguaje, remite a una precisión mayor alrededor de la significación y uso de un determinado andamiaje o estructura. Al cuestionar esta condición, Cioran se enfrenta a un aspecto digno de tener en cuenta. ¿No es la escritura una creación verbal donde se pone en evidencia la creatividad artística que en gran medida ha definido gran parte de la tradición filosófica? ¿No es esta una objeción que puede hacérsele al rumano al reflexionar sobre su ataque visceral a los aspectos hasta ahora señalados? La filosofía ha sido desde su origen en Platón — se hace referencia aquí a la filosofía escrita, a la filosofía como un género literariouna puesta en escena, un proceso creativo en el cual se pone en juego una serie de manifestaciones de índole estética que convergen en el estilo. De esta manera, lo que el propio Heidegger realizó hace también parte de esta especificidad de un género literario llamado filosofía, la cual no puede considerarse al margen de un estilo. ¿Qué es entonces lo que Cioran rechaza con vehemencia? Principalmente una elección escritural que descolló ampliamente en el pasado siglo, desde la cual se privilegió el lenguaje convirtiéndolo en protagonista, y en ciertos casos puntuales, objeto de una veneración extrema llevada al paroxismo signado por la oscuridad que lo caracterizó.

Al indicar cómo la filosofía en el pasado siglo logró desplegarse a través de una muy frecuente elección de la ambigüedad y la oscuridad en materia escritural, Cioran ataca con ímpetu esta manifestación. Las alusiones al estilo y al lenguaje no son pocas en él. Apuntan a una elección y sobre todo, tal como lo indica en la pasada cita, a una necesidad de quien está constreñido por una manía que en cierta

1 Todas las traducciones al español son realizadas por el autor del artículo.

« Heidegger et Céline — deux esclaves de leur langage, au point que pour eux s’en libérer équivaudrait à disparaitre. S'asservir à sa propre manière, il y entre de la nécessité, du jeu, et de l'imposture. Comment démêler la part de chacun de ces éléments? Reste que le phénomène primordial est la nécessité. C'est ce qui absout les maniaques du langage à eux ». 
medida, es más importante que el pensamiento mismo. Sobre esta particular crítica que Cioran expresa varias veces, es imprescindible definir el sentido que se desea resaltar en torno a ella.

La voluntad de ser profundo, de hacer profundo, consiste en forzar el lenguaje evitando a cualquier precio la expresión normal, la expresión inevitable. Ninguna lengua favorece tanto este exceso, este abuso, como el alemán. A todas luces el genio de Heidegger es un genio verbal. Su habilidad para salir de un callejón sin salida viene de su facilidad para camuflarlo usando todos los recursos del lenguaje, inventando giros insólitos a menudo atractivos, en ocasiones desconcertantes, por no decir exasperantes (Cioran, 2009, p. 63). ${ }^{2}$

El afianzamiento de una estilística dentro de un derrotero filosófico se destaca como un manifiesto imprescindible de lo que significa para Cioran un compromiso vital que se reproduce en la escritura. Por ello, una filosofía que pervierta esta condición para tornarse esclava del lenguaje, y principalmente, de un exceso o abuso que lo fuerza a representar una profundidad aparente, implica un juego que tiene en el lenguaje, y en sus rodeos, toda su finalidad. Una profundidad que se afiance en la capacidad para llevar el lenguaje a sus límites, es ya una fachada, una transgresión que tiene ya en sí misma su sentido, marginando o mejor, dejando atrás, el pensamiento, la idea, la constitución directa de lo que se vive. En general, Cioran no ve con muy buenos ojos los procesos filosóficos en tanto a partir de la abstracción, desconocen justamente las vivencias directas. Si esa abstracción se ejecuta además con la excitación lingüística de un autor que pareciera estar más preocupado por la oscuridad de sus elucubraciones, entonces los resultados no pueden ser más que divagaciones que no llevan a ningún lugar.

Ahora bien, otro aspecto que Cioran se permite destacar en La tentación de existir revela una estimación problemática en lo que respecta al propósito de la elección y ejecución de un estilo dentro de la escritura filosófica. La filosofía propiamente no puede excluir el estilo, toda composición escrita implica uno. Acaso permeado por cierto pudor platónico, Cioran parece confrontar la sofística y desestimar sus propósitos cuando escribe:

2 «La volonté d'être profond, de faire du profond, consiste à forcer le langage en évitant à tout prix l'expression normale, l'expression inévitable. Aucune langue ne favorise autant que l'allemande cet excès, cet abus. De toute évidence le génie de Heidegger est un génie verbal. Son habilité à sortir d'une impasse vient de sa facilité à la camoufler en usant de toutes les ressources du langage, en inventant des tournures insolites souvent séduisantes, parfois déconcertantes, pour ne pas dire exaspérantes ». 
Experimentados en un arte de pensar puramente verbal, los sofistas fueron los primeros en reflexionar sobre las palabras, sobre su valor y su propiedad, sobre la función que les correspondía en el manejo del razonamiento: el paso capital hacia el descubrimiento del estilo, concebido como objetivo en sí, como fin intrínseco, estaba dado (Cioran, 2011, p. 894). ${ }^{3}$

Pero en realidad se trata de un texto equívoco, en él, Cioran no revela simplemente una condena a la sofística, propiamente expone con una ambigüedad característica en él cómo el estilo es ineludible dentro de la exigencia que tiene lugar en el proceso de escritura. No solamente restituye la importancia del estilo desde una consideración estética, converge además una estimación escéptica frente al abordaje de la realidad. Involucra el hecho de valorar el estilo como un fin en sí mismo, en vista del carácter distante de la realidad. Por ello llega a decir: "Vincular todo esto a la experiencia del estilo (...) el estilo como la forma suprema de nuestra realidad, de nuestra nada" (Cioran, 2011, p. 1389). ${ }^{4} \mathrm{Y}$ es que no puede haber sino imprecisión o vaguedad con respecto a una realidad esquiva. El estilo así revela un carácter poético o fabulador en el que cobra todo su sentido, pues su pertinencia deja de inscribirse en el ámbito de ser tan sólo un maquillaje que cubra un fondo, sino que aparece él mismo como el único fondo. Análogamente Nietzsche lo plantea cuando determina el carácter capital de la apariencia.

Se es artista al precio de sentir como contenido, como "la cosa misma", aquello que todos los no artistas llaman "forma". Con lo cual, ciertamente, se entra a formar parte de un mundo invertido: pues desde ese momento el contenido se convierte en algo meramente formal, —incluso nuestra vida (Nietzsche, 2008, p. 11 [3]).

Este aspecto plástico en efecto constituye un elemento poético. La forma, el estilo, será así el único contenido que refleja un mundo sin sustancia. En efecto, el mundo de quien se asume escéptico.

Por supuesto, desde el escepticismo de Cioran se realza el estilo en vista de que una realidad que esté más allá de la palabra no puede ser fundada. Nada justifica más este énfasis en la concreción de una estilística que la imposibilidad

3 «Rompus à un art de penser purement verbal, les sophistes s'employèrent les premiers à réfléchir sur les mots, sur leur valeur et leur propriété, sur la fonction que leur revenait dans la conduire du raisonnement : le pas capital vers la découverte du style, conçu comme but en soi, comme fin intrinsèque, était franchi ».

4 « Relier tour cela à l'expérience du style (...) le style comme la forme suprême de notre réalité, de notre flou ». 
de registrar una precisión original en cualquier abordaje. Por ello, es comprensible precisar cómo:

Toda idolatría del estilo parte de la creencia de que la realidad es aún más hueca que su figuración verbal, que el acento de una idea vale más que la idea, un pretexto bien logrado más que una convicción, un giro sabiamente hecho más que una irrupción irreflexiva. Ella exprime una pasión de sofista, de sofista de las Letras. Tras una frase proporcionada, satisfecha de su equilibrio o hinchada por su sonoridad, se oculta a menudo el malestar de un espíritu incapaz de acceder por la sensación a un universo original. ¿Qué asombroso es que el estilo sea tanto una máscara y una confesión? (Cioran, 2011, p. 901). ${ }^{5}$

La imposibilidad de acceder a un universo original. En tal expresión se identifica toda la importancia concedida al estilo no simplemente como estímulo o efecto de carácter retórico sino como consumación de una precisión estética desde la cual, por ello, la forma vale más que el contenido, o mejor, es el único contenido.

$\mathrm{Y}$ es que precisamente, no puede olvidarse que el mismo autor ha podido ejercer su oficio escritural a partir de una escogencia estilística. A raíz de eso, es posible igualmente pensar que su comprensión de la filosofía a partir de un uso estilístico se establece también y necesariamente en él. No podría ser de otra manera. Apelar a un estilo, sea cual sea, es una necesidad, por ello la crítica de Cioran en torno al oscurantismo estilístico sólo puede ser válida en la medida de especificar su rechazo no a la elección de un estilo, sino a un estilo en particular signado por la confusión y la oscuridad. En ese sentido, Cioran reitera su perspectiva cuando expone cómo la estilística contemporánea de la filosofía no es más que una retahíla de abstracciones vagas, improcedentes y fatuas. Así lo revela en un oportuno comentario al respecto, cuando advierte sobre la renuncia a la claridad a partir de la opción estilística que identifica oscuridad y profundidad:

Intrincados sin misterio, alambicados sin sutilidad, giran alrededor de un problema hasta que logran hacérnoslo odioso. De igual manera, son incomprensibles, marca primera de "profundidad". Su pensamiento no

5 « Toute idolâtrie du style part de la croyance que la réalité est encore plus creuse que sa figuration verbale, que l'accent d'une idée vaut mieux que l'idée, un prétexte bien amené qu'une conviction, une tournure savante qu'une irruption irréfléchie. Elle exprime une passion de sophiste, de sophiste des Lettres. Derrière une phrase proportionnée, satisfaire de son équilibre ou gonflée de sa sonorité, se cache trop souvent le malaise d'un esprit incapable d'accéder par la sensation à un univers originel. Quoi d'étonnant que le style soit tout ensemble un masque et un aveu ?». 
avanza ni retrocede: gira en círculos, sin ninguna progresión, ni fórmula que, al menos, podría animarlo, hacerlo brillante, prestarle alguna seducción (Cioran, 2009, p. 65). ${ }^{6}$

El papel marginal que Cioran representa dentro del pensamiento contemporáneo se expresa y se explica en buena medida (no en toda por supuesto) a partir del anterior fragmento. La exclusión que él mismo se da, desde la cual contradice los estereotipos que marcaron el siglo XX en materia filosófica a partir de la constante apelación a la oscuridad estilística, se explica en gran parte por esta preocupación estilística que no es poca y mucho menos superflua. En ella convergen el ya abordado enfoque teórico sobre el problema así como la expresión práctica desplegada en su propio ejercicio escritural. Con respecto a esta última, son varios los aspectos desde los cuales se puede evidenciar y esclarecer. Uno de los aspectos sobre los que Cioran enfatizó dentro del aprendizaje y perfeccionamiento del francés como lengua en la que afianzaría su ocupación escritural, se distingue a través de la elección de un estilo en el cual la poesía y en general lo poético tiene una importancia mayúscula.

\section{La elección estilística y la poesía}

La exigencia de corrección, para delinear un estilo en los textos que conformarían su primer libro en francés, Précis de décomposition, es bien conocida y documentada. ${ }^{7}$ Además de la plenitud que lograría después de reescribirlo al menos cuatro veces, es también importante destacar cómo esta preocupación por el estilo deriva de un encuentro con la poesía.

El interés que Cioran despliega por ella y por el lirismo se ve concretado significativamente en buena parte de su obra rumana, aunque también específicamente en Breviario de podredumbre y La Tentacion de Existir. Se hace aquí referencia a la concreción estilística pues es claro que buena parte de la obra francesa empieza a adquirir un tono más despoetizado, abandona el tono lírico precisando un ámbito cada vez más escéptico que intenta especificar una tonalidad

6 « Tortueux sans mystère, alambiqués sans subtilité, ils tournent autour d'un problème jusqu'à ce qu'ils réussissent à nous le rendre odieux. De plus, ils sont incompréhensibles, marque première de « profondeur ». Leur pensée n'avance ni ne recule : elle tourne en rond, sans aucune progression, ni formule qui, du moins, pourrait l'animer, la rendre brillante, lui prêter quelque séduction ».

7 Al respecto puede rastrearse esta obsesión en Notice et notes sur Précis de décomposition (Cavaillès, 2011 p. 1301 y ss.). 
enteramente crítica. En ambas etapas por supuesto, hay una voluntad de estilo que es lo suficientemente explícita, lo que cambia es el arraigo hacia una determinada experiencia sea lírica o escéptica (crítica). No se trata simplemente de un cambio de lengua como podría pensarse, al asumir que una y otra etapa se expresa a partir del periodo rumano o francés. Tal como el mismo autor lo confirma, el tono lírico y poético se puede detallar aun en los libros franceses señalados arriba, aunque sea claro que desaparece cada vez más en la obra francesa a partir de la publicación de Historia y utopía en 1960. El hecho es que esta sujeción a la etapa lírica comienza a ser contrastada por el propio autor en textos posteriores a partir de una experiencia crítica auto-infligida. En todo caso, tal como acontece con otros aspectos, no es posible ni tampoco necesario indicar una posición definitiva o absoluta. Es claro que tanto el estilo consignado en la lírica como en el de una prosa más ácida y crítica corresponden a facetas que Cioran desplegó en diferentes etapas, y desde ellas, retrospectivamente, el autor realiza así mismo una poética, es decir, una preceptiva y análisis de su propia escritura que se ve plasmada fundamentalmente en sus Cahiers. Tal como se verá más abajo, estos fragmentos constituyen una muy precisa indicación crítica que Cioran realiza sobre su obra. En ese sentido: "Los Cuadernos son una inmensa ars poética, en la cual se analiza, por el proceso de construcción-deconstrucción, la escritura que se hace o se ha hecho. Cioran no se limita a un comentario de sus textos, sino partiendo de allí, construye su propia teoría del hacer poético (Stânisor, 2003, p. 181). ${ }^{8}$

Ahora bien, con respecto a la poesía, y al fenómeno de su recepción e influencia en la escritura de su primer libro francés, se evidencian algunos aspectos tales como:

Durante la ocupación, y especialmente bajo la influencia de su compañera Simone Boué, joven profesora de inglés, Cioran, quien toma por entonces cursos de inglés, se sumerge en la poesía romántica inglesa. El primero de enero de 1940 escribe a Mircea Eliade: "la felicidad no puede concebirse en otro lado sino en un hotel parisino, leyendo poetas ingleses y en soñar sin ideas, en la ola de una ausencia de espera"; lee entonces Skakespeare, Elizabeth Barret Browning, y sobre todo Shelley, el Epipsychidion, o bien el poema "Stanzas written in Dejection Near Naples"(Cavaillès, 2011, p. 1309). ${ }^{9}$

8 «Les Cahiers sont un immense ars poetica, dans lequel est analysée, par le processus de constructiondéconstruction, l'écriture en train de se faire ou déjà fait. Cioran ne se limite pas à un commentaire de ses textes, mais en partant de cela, il construit sa propre théorie du faire poétique ».

9 « Durant l'Occupation, et notamment sous l'influence de sa compagne Simone Boué, jeune agrégée d'anglais, Cioran, qui suit alors des cours d'anglais, se plonge dans la poésie romantique d'outre- 
Con estas lecturas, y la de algunos otros poetas, configura, planea y ejecuta la redacción de su Précis. Durante su composición, son muchas las lecturas en las que se incluyen nombres asociados a la poesía. De hecho, Cioran mismo describe cómo el poema Stanzas written in Dejection near Naples de Shelley, "resume él solo muchos años de mi vida, y quizás, mi vida. En cierto sentido, todo el Breviario no es más que una variación sobre ese poema" (Cioran, 1997, p. 824). ${ }^{10}$ La influencia de un lenguaje altamente subjetivo y lírico en la escritura de este libro también es reconocida por Rigoni, amigo del autor, cuando deja entrever las similitudes que existen entre el Breviario y su primer libro rumano En las cimas de la desesperación. Muestran además las conexiones que aun en este periodo de escritura, unen a Cioran con un lenguaje poético y lírico que tal como se señaló, irá desapareciendo en el periodo francés.

Su primer libro escrito en rumano y publicado en Bucarest en 1934, se parece mucho - por su estructura, sus temas, su ritmo febril, al Breviario (...) las meditaciones del Breviario evocan con mayor fuerza inclusive los Pequeños poemas en prosa. Tenemos derecho a lamentar que Cioran, unido ciertamente a Baudelaire por un lazo completamente especial de devoción y afinidad, no se haya referido jamás al respecto, pues nada es más intrigante que el nacimiento de una obra maestra. Creo no obstante, que él pudo encontrar en El Spleen de Paris su modelo formal (Rigoni, 2009, pp. 54-55). ${ }^{11}$

Debe resaltarse cómo esta obsesión por el estilo y por la poesía involucra además la muy relevante figura de Valéry. Es notoria la influencia ejercida por el poeta francés dentro de la comprensión que Cioran hace de su propia actividad escritural. De hecho, le atribuye el dominio que hizo de la lengua francesa gracias a la obsesión que el poeta tenía por el estilo y por el trabajo perseverante alrededor de la construcción poética.

Manche. Le Ier janvier 1940, il écrit à Mircea Eliade que « le bonheur ne peut se concevoir ailleurs que dans un hôtel parisien, à lire des poètes anglais et à rêver, sans idée, dans le vague d'une absence d'attente »; il lit alors Shakespeare, Elizabeth Barret Browning, et surtout Shelley, l'Epipsychidion, ou bien le poème «Stanzas Written in Dejection Near Naples ».

10 «Résume à lui seul plusieurs années de ma vie, et, peut-être, ma vie. En un certain sens, tout le Précis n'est qu'une variation sur ce poème».

11 «Son premier livre, écrit en roumain et publié à Bucarest en 1934, ressemble fort — par sa structure, ses thèmes, son rythme fébrile—au Précis (...) les méditations du Précis évoquent avec plus de force encore les Petits Poèmes en prose. On est en droit de regretter que Cioran, certainement uni à Baudelaire par un lien tout à fait spécial de dévotion et d'affinité, ne se soit jamais exprimé là-dessus, car rien n'est plus intrigant que la naissance d'un chef-d'œuvre. Je crois cependant qu'il aurait pu trouver dan Le Spleen de Paris son modèle formel ». 
Sin embargo, la presencia de Valery en la composición del Précis no es un asunto meramente estilístico. Las fuentes valerianas a las cuales Cioran acude con prontitud, específicamente en el libro citado, están referidas también a ciertos tópicos e intereses temáticos bastante puntuales. De hecho, en Valery, Cioran sitúa con precisión una muy significativa relación entre estilo y contenido. En primer lugar,

su "práctica" asidua de la obra de Valery se inscribe también en el cuadro de su alejamiento irreversible con respecto a la filosofía: si Chestov, destructor de la tradición filosófica racionalista, le había proporcionado los argumentos, Valery ofrece a Cioran una escapatoria, otro aspecto intelectual cuyo extremo refinamiento prohíbe la pesadez de la jerga filosófica, a la cual no se sacrificará nunca más (Cavaillès, 2011, p. 1310). ${ }^{12}$

Por ello, la lectura de este poeta tiene una enorme correspondencia con su alejamiento de la filosofía academicista, alejamiento que por supuesto ya venía gestándose desde hacía mucho tiempo. A partir, sin embargo, de la influencia valeriana, cobra un matiz más definido y también más centrado. Si bien se trata de una distancia de la filosofía en lo que concierne principalmente a su propensión a una jerga academicista, Valery le proporciona además una reflexión e influencia directa sobre asuntos estilísticos.

La concentración e interés por el estilo está completamente ligada a la puesta en escena de un escenario nihilista previo. Tal como se especificó antes a partir de la cita de Nietzsche, el estilo cobra mayor importancia y vigencia, máxime en Valery, quien se ampara en un 'fundamento' nihilista. En una entrevista, Cioran cita al poeta francés considerando una frase que desde su punto de vista es crucial para la comprensión del entorno nihilista que encierra la adopción y alta significación de una estilística: "La palabra es la única manera de multiplicarnos en la nada". ${ }^{13}$ El estilo como refugio ante la significación nihilista de un mundo que carece de sustancialidad. Cioran por supuesto, liga su fascinación estilística ante una temática que lo circunda y lo obsesiona, sin que por ello, haya de definirse en él una expresión definitiva en lo que concierne tanto al poeta francés como a la poesía en general.

12 «Sa «pratique » assidue de l'œuvre de Valéry s'inscrit aussi dans le cadre de son éloignement irréversible vis-á-vis de la philosophie : si Chestov, pourfendeur de la tradition philosophique rationaliste, lui en avait fourni les arguments, Valéry offre à Cioran une échappatoire, un ailleurs intellectuel dont l'extrême raffinement interdit la lourdeur du jargon philosophique, auquel il ne sacrifiera plus jamais ».

13 «Le mot est le seul moyen de nous multiplier dans le néant » En Entretien avec Dominique Arban. E.M. Cioran, écrivain roumain, est devenu un écrivain français. Le Figaro littéraire, julio 1 de 1950, p. 6. 
Desde una perspectiva posterior y autocrítica, la influencia de la poesía en sus escritos es valorada con reserva. Así lo deja ver en sus Cahiers cuando expresa cierta inconformidad, al considerar cómo en la poesía contenida tanto en su Précis como en La Tentation, deja al descubierto un gusto obsoleto, "romántico". ${ }^{14}$ Es bastante atractiva esta posición de Cioran en la medida que contradice justamente el estilo al cual le hemos dado tanta importancia y estima. Para el autor, el lirismo derivado de su adhesión a la poesía romántica contaminó sus textos a tal punto de tener que considerar un cambio, una orientación distinta que le permitiese extraerse del mismo para asumir una rigurosidad necesaria que le hiciera cambiar sus apegos líricos, liberarse de ellos. "No ceder a la tentación del lirismo, liberarse de los hedores nietzscheanos (...) La necesidad de rigor prevalece en mí sobre la histeria (Cioran, 1997, p. 417). ${ }^{15}$ Estas apreciaciones que confrontan sus propios textos envuelven cierta necesidad de autocrítica, la cual es cínica y lúcida al mismo tiempo. El descontento por los efectos de sus lecturas románticas, de sus apegos líricos, muestra que la obsesión por el estilo continúa siendo una confrontación que ante todo, reaviva el proceso creativo de Cioran, tal como se señaló supra en relación al ars poetica que desarrolla en sus Cahiers. De esta manera, corrobora la necesidad de estimular su actividad enfatizando en la tonalidad escritural desde otra índole que confronta los "peligros" de la poesía y su obsesión lírica. Señalan también, los cambios operados a partir de la adopción del francés, las transformaciones que se dan cada vez más, al adoptar una lengua cuyas características

$$
\begin{aligned}
& \text { se oponen diametralmente a su naturaleza impulsiva, inclinada al } \\
& \text { apasionado desorden que se trasluce en sus primeros libros en rumano. (...) } \\
& \text { Esta lengua (el francés), ideal para exposición límpida de los "suspiros del } \\
& \text { intelecto", pero inhábil para el delirio, le obligó a refrenar sus arrancadas } \\
& \text { temperamentales y a tomar distancia de sus propios pensamientos (Marín, } \\
& \text { 2001, p. 205). }
\end{aligned}
$$

Además de exaltar los vínculos que unen un estilo definido a través del lirismo con las raíces trágicas del hombre, Cioran igualmente intenta luego desvincularse de esta particularidad escritural centrándose en su confrontación escéptica frente al hombre. En ese sentido,

$14 C f$. Cioran (1997 p. 336). De igual manera el distanciamiento que toma en referencia a Valéry, en el que indica la experiencia frustrante de haberlo tomado como modelo. Cf. Cioran, 1997, p. 562.

15 «Ne pas céder à la tentation du lyrisme, se dégager des relents nietzschéens (...) Le besoin de rigueur l'emporte chez moi sur l'hysterie ». 
Cioran es un admirador del abismo, de la a menudo monstruosa y brutal grandeza de la naturaleza, pero, en cambio, es un crítico vital del hombre, cuyo ser dedálico y maléfico le repulsa, cuyos defectos exigen su sarcasmo. Cioran permanece fiel a la idea de que la grandeza de la humanidad no es nada sino una hipótesis presuntuosa, imposible de confirmar de acuerdo con los hechos de la experiencia (Valcan, 2013, p. 192). ${ }^{16}$

Precisamente, es comprensible por qué opta posteriormente por un estilo mucho más ácido con el cual sea acogida la decepción escéptica que se despliega en muchos de los textos del periodo francés en los cuales su orientación crítica hacia las posibilidades del hombre es explícita.

Una descripción que contrasta el estilo que Cioran utiliza en el primero de sus libros en rumano con el que aborda en su Breviario clarifica aún más estas particularidades y enfoques de su escritura.

Después de una lectura comparativa de los textos, constatamos que las llamas del patetismo del discurso en rumano se apagan gradualmente en francés, de un libro a otro, y dan lugar a la felicidad del escepticismo. En $\mathrm{Pe}$ culmile disperãrii es tocado por el lirismo explosivo de un discurso barroco, lleno de comparaciones o de metáforas y de paradojas, parecido al estilo de Nietzsche o de Kierkegaard, los maestros de su juventud, provocando en la densidad de la expresión, un efecto de choc. (...) En el Breviario de Podredumbre, la reflexión sobre el yo se conceptualiza tanto que el discurso parece una meditación cartesiana, acompañada de la conciencia de un moralista de la escuela de Montaigne o de Pascal (Chioaru, 2015, pp. 127128). ${ }^{17}$

Tal como fue detallado más arriba, no se trata pues de un cambio inmediato sino progresivo, pues a pesar de los matices descritos en la anterior referencia en

16 « Cioran is an admirer of the abysmal, of the often monstrous and brutal grandeur of nature but, in exchange, he is a vital critic of man, whose Daedalic and malefic being repulses him, whose shortcomings call for his sarcasm. Cioran stays faithful to the idea that the grandeur of humanity is nothing but a presumptuous hypothesis, impossible to confirm according to the facts of experience ».

17 « Après une lecture comparative des textes, on constate que les flammes du pathétisme du discours roumain s'éteignent graduellement en français, d'un livre à l'autre, et laissent place au bonheur du scepticisme. Dans Pe culmile disperãrii, on est frappé par le lyrisme explosif d'un discours baroque, plein de comparaisons ou de métaphores et de paradoxes, ressemblant au style de Nietzsche ou de Kierkegaard, les maitres de sa jeunesse, et provoquant, dans la densité de l'expression, un effet de choc (...) Dans le Précis de décomposition, la réflexion sur le moi se conceptualise tellement que le discours ressemble à une méditation cartésienne, accompagnée de la conscience d'un moraliste de l'école de Montaigne ou de Pascal ». 
torno al Précis, allí igualmente existen pautas poéticas y líricas. Lo que sí es claro es que cada vez más Cioran se va alejando de ellas para introducirse en un enfoque distinto. A pesar de que esta perspectiva crítica da al traste con la fascinación poética que se ha descrito hasta ahora, muestra justamente la capacidad que Cioran expone al poder revisar y confrontar su propia escritura y en este caso particular, la expresión fervorosa que la impregna. En este sentido, es necesario considerar esta característica y exponer la relación que la poesía y su expresión lírica tienen dentro de la escritura en la primera etapa del autor.

\section{Cioran y la lírica (adopción y rechazo)}

La influencia de la poesía es pues, suficientemente amplia. Pero no sólo de la poesía como género, sino del aspecto que involucra lo poético como ámbito lírico que manifiesta gran parte de la escritura cioraniana. Tal como ocurre con otras facetas que envuelven tanto el estilo como los contenidos cioranianos, en esta se revela una descripción ambivalente. Es innecesario repasar todas las manifestaciones líricas contenidas en la obra del autor, aunque sí destacar que se presentan con mayor amplitud en su obra rumana. Esta manifestación se puede caracterizar como una filosofía lírica que está determinada por la asimilación de las fuentes irracionales y trágicas que envuelven la experiencia humana. Es a partir de este contexto como se resalta este tipo de escritura desde el cual: "La filosofía lírica implica aquella agonía, a la que se precipita el auténtico creador mediante el método cioraniano. Sólo así se puede registrar, escrutar, en definitiva, sufrir y finalmente expresar el fondo irracional que se desvela tras la existencia acechada por la muerte" (Gajardo, 2018, p. 89).

La expresión verbal que deriva de las lágrimas, la evocación del paraíso, las efervescencias que el sufrimiento causa, el fracaso propio del hecho de existir, los desvaríos generados por el insomnio, la expresión flamígera del obseso, se expresan en no pocos párrafos destinados a la exaltación lírica. En este mismo sentido se afianza la idea de cómo esta clase de escritura está ligada enteramente al cuerpo, a la especificidad de un pensamiento que deriva de la constitución orgánica y vital que envuelve al primero y por medio de la cual se resalta un tipo de penetración inmediata, que deja descubrir los gritos de su insuficiencia. Así, "el lenguaje desborda su artificio para volver a la carne, de la que este y el pensamiento nacen" (Izquierdo, 2013, p. 53). 
Por eso, poco podría comprenderse el pensamiento cioraniano si se desconociera su manifestación lírica, su expresión más íntima. Lo es porque las experiencias que se destacan en el recorrido vital del autor son las que concuerdan más con los exaltaciones subjetivas y personales que lo envuelven. Y justamente en ello, en esa particularidad tan íntima, personal y manifiesta en revelaciones poéticas a las cuales la escritura cioraniana no es ajena, se revela también una conexión amplia con el mundo de la generalidad a la que tanto ansía llegar la filosofía.

Justo en el texto que abre su primer libro, En las cimas de la desesperación, escrito en rumano, Cioran consigna un aspecto revelador:

Las experiencias subjetivas más profundas son también las más universales en aquello que unen al fondo original de la vida. La verdadera interiorización conduce a una universalidad inaccesible a quienes permanecen en lo inesencial y para quienes el lirismo sigue siendo un fenómeno interior, producto de una inconsistencia espiritual, mientras que los recursos místicos de la subjetividad declaran, en realidad, una frescura y profundidad interiores más remarcables (Cioran, 2011, p. 20). ${ }^{18}$

Esta defensa de las expresiones líricas, la cual no está circunscrita a una recepción meramente estilística, desemboca en una definición filosófica de la poesía. Que a partir de un atributo subjetivo exaltado se identifique una percepción universal es en realidad una idea similar a la que el mismo Aristóteles había expresado cuando en la Poética exaltaba el papel y la "función" de la poesía indicando cómo era más filosófica que la historia en la medida de identificarse no con lo particular sino con lo general ( $c f .1451 b)$. Si bien el estagirita hace referencia también al hecho de que la poesía puede manifestar no sólo lo que ha sucedido como lo hace la historia, sino lo que podría suceder, es decir, todas las proyecciones que nacen a partir del carácter creativo y artístico que la envuelve, las palabras de Cioran no se alejan mucho del sentido amplio que revela el texto antiguo. Y es que en el carácter lírico y expresivo que tenía la tragedia antigua, por ejemplo, es en donde los espectadores podían reconocer la universalidad a partir de un medio particular. ${ }^{19}$ No es otro el sentido que tiene en gran medida el manifiesto dionisíaco de la representación trágica que

18 «Les expériences subjectives les plus profondes sont aussi les plus universelles en ce qu'elles rejoignent le fond originel de la vie. La véritable intériorisation mène à une universalité inaccessible à ceux qui en restent à l'inessentiel et pour qui le lyrisme demeure un phénomène inferieur, produit d'une inconsistance spirituelle, alors que les ressources lyriques de la subjectivité témoignent, en réalité, d'une fraîcheur et d'une profondeur intérieures des plus remarquables ».

19 Esta idea la desarrolla Ricoeur cuando explora la facultad mimética de la tragedia griega y cómo su representación tenía un efecto sobre el espectador. (Ricoeur, 2004, p. 139 y ss.). 
Nietzsche precisa en El nacimiento de la tragedia, la conjunción unitaria y universal que desde procesos individuales como los del héroe trágico, se proyectan en un único acogimiento. El lirismo, al cual Cioran confiere la posibilidad de ser agente de un conocimiento universal, no está exento de fundamento en lo concerniente a las posibilidades que entrega y a las revelaciones que se extraen de sus profundidades.

Tal como lo establece Cioran en la cita anterior, Nietzsche interpreta el papel de la lírica antigua desde posiciones análogas. La asimilación de la lírica como poseedora de un carácter subjetivo es cuestionada por el filósofo alemán para destacar justamente lo contrario: la lírica y su constitución eminentemente objetiva y por lo tanto, universal.

Ya en el proceso dionisiaco el artista ha abandonado su subjetividad: la imagen que su unidad con el corazón del mundo le muestra ahora es una escena onírica, que hace sensibles aquella contradicción y aquel dolor primordiales junto con el placer primordial propio de la apariencia. El "yo" del lírico resuena, pues, desde el abismo del ser: su "subjetividad", en el sentido de los estéticos modernos, es pura imaginación (Nietzsche, 1997, p. 63).

Tanto Cioran como Nietzsche establecen un puente entre la individualidad desde la cual se desprende la sensibilidad lírica y la universalidad a la cual esa misma sensibilidad se eleva.

La expresión lírica deja de tener en todo caso la valoración positiva que se plasma en algunos de los textos cioranianos. En otros, por el contrario, se expresa un rechazo y animadversión profundos. Además de la recepción que Cioran hace de la mística, por ejemplo, y de la cual dan cuenta varios textos en los que se revela no sólo el interés sino el apasionamiento por los arrebatos místicos que se plasman en expresiones líricas, Cioran destaca también la necesidad de distanciarse de la misma a partir de una toma de posición crítica frente al lirismo principalmente. ${ }^{20}$

20 En la obra de Cioran se acentúa el interés por la mística desde consideraciones que involucran el tema bajo dos ópticas distintas. En primer lugar, el rumano hace manifiesto un acercamiento a partir de una crisis religiosa propia en la que está comprendida entonces una manifestación directa e inmediata precisada en la plegaria cioraniana, el lirismo de una religiosidad equívoca y su materialización en la escritura, conformando una serie de textos enmarcados explícitamente en la condensación de un misticismo por supuesto siempre ambiguo. Por otra parte, Cioran confronta, analiza, esquematiza también la mística a través de una postura crítica, desde la cual proporciona una síntesis del vivo interés por la temática, así como la expresión de un pensador que a distancia, asume su "objeto". En Cioran se destaca entonces tanto al místico como el pensador, el lírico que canta desde las profundidades de su abismo como el agente crítico que expresa su postura en torno a un tema que si bien lo atrae, al mismo tiempo es capaz de postularlo desde una exigencia racional ciertamente equilibrada. 
El distanciamiento del lirismo irrumpe a partir de una serie de posiciones críticas en las que intenta reivindicar el uso de una prosa cínica y desencantada. De esta manera, precisar la independencia de todo efecto lírico y poético parece ser el propósito de un Cioran mucho más comprometido con su papel de moralista. El paso de la exacerbación lírica y poética hacia una prosa que intenta exponer una actitud más racional, desencantada, crítica y corrosiva, hace manifiesta la evolución del pensador. Esta transformación no sólo se desarrolla dentro de un terreno estético. A partir de este cambio, el rumano expone un pensamiento cada vez más enfocado en el escepticismo y el moralismo.

Es sobre todo en los Cahiers en donde pueden encontrarse numerosas referencias que rechazan la adhesión lírica que tanto caracterizó al pensador. Así lo plantea en un fragmento de 1957: "Mi ideal de escritura: callar para siempre al poeta que se oculta en sí; liquidar sus últimos vestigios de lirismo; ir a contra corriente de aquello que se es, traicionar sus inspiraciones; pisotear sus impulsos y hasta sus gestos" (Cioran, 1997, p.14). ${ }^{21}$ Esta apreciación remite a otra mirada, a otra consideración en torno a los propósitos que el escritor desea concretar. Cioran pretende reemplazar el lirismo por una prosa que intenta despoetizar, aliviándose de la fiebre lírica a partir de un desencantamiento que tenga en la actitud crítica su más fuerte aliado.

Este cambio muy significativo que involucra la puesta en marcha de un estilo distinto que ha sido previamente meditado, pasa también por una caracterización del propósito al cual apunta Cioran. Si puede llegar a decir que: "Paso por un periodo en el que ni la poesía ni la mística me dicen algo. El lirismo, bajo cualquier disfraz que se presente, me produce el efecto de un vomitivo. Sólo me agrada la prosa ácida y corrosiva" (Cioran, 1997, p. 190). ${ }^{22}$ Esto es porque para él es necesario cambiar de dirección en la medida de comprometerse con una posición más próxima al moralismo, es decir, al retrato incisivo del hombre desde una perspectiva que se asuma lúcida y desencantada. De nuevo entonces, un Cioran en el cual el pensamiento está ligado a un estilo. En este caso, definido por la exigencia moralista de acceder al hombre a partir de la lucidez necesaria que sólo, renunciando a la

21 «Mon idéal d'écriture : faire taire à tout jamais le poète qu'on recèle en soi ; liquider ses derniers vestiges de lyrisme ; - aller à contre-courant de ce qu'on est, trahir ses inspirations ; piétiner ses élans et jusqu'à ses grimaces ».

22 « Je passe par un période où ni la poésie ni la mystique ne me disent rien. Le lyrisme, sous quelque déguisement qu'il se présente, me fait l'effet d'un vomitif. La prose acide, corrosive, seule m'agrée ». 
poesía y la lírica, puede alcanzar. Si "El primer deber de un moralista es despoetizar su prosa" (Cioran, 1997, p. 218), ${ }^{23}$ entonces este imperativo expresado en los Cahiers obedece a una exigencia que proyecta una mirada desprovista de la emotividad lírica. El moralismo enfocado en la expresión y descripción crítica del hombre, tal como lo dejó plasmado en los muchos textos en los que se despliega una mirada especialmente ajena al dramatismo lírico, sujeta a la concepción desengañada de una interpretación especialmente negativa del hombre.

Ante las dos posturas adversas que caracterizan la escritura cioraniana en torno a la lírica, es preciso indicar cómo esta contradicción puede llegar a explicarse. Se trata de dos percepciones integradas en un mismo escritor. Inmerso en varias ambigüedades, Cioran en este caso destaca una más. En realidad, poesía (lírica) y prosa fluyen en él de manera alternativa, a partir de una oposición que debe entenderse como la confluencia de agentes que se excluyen aunque también en dicho proceso, se alimenten recíprocamente. Tal experiencia la describe muy bien Nietzsche:

Los grandes maestros de la prosa han sido casi siempre también poetas (...) isólo en vista de la poesía se escribe buena prosa! Porque esta es una ininterrumpida guerra cortés con la poesía: todos sus atractivos consisten en esquivar y contradecir constantemente a la poesía; toda expresión abstracta quiere ser una travesura frente a aquella y decirse como con una voz burlona; toda sequedad y frialdad deben llevar a la graciosa diosa a una graciosa desesperación (Nietzsche, 2014, § 92).

Este fragmento permite comprender un aspecto decisivo de la cuestión estilística que se destaca en la oposición establecida en la práctica escritural cioraniana. El autor ante todo, fue efectivamente un maestro que conserva las mismas características que establece el texto nietzscheano, y en suma, las oposiciones necesarias para poner en tensión dos momentos que igualmente dejan clara la ambivalencia y riqueza de su estilo.

\section{Poesía y lirismo: remedios contra la abstracción}

Como crítico de la abstracción filosófica, en la medida de resaltar el papel fundamentalmente individual, personalmente padecido de las experiencias que

23 «Le premier devoir d'un moraliste est de dépoétiser sa prose». 
conducen a sus reflexiones, Cioran confiere un papel fundamental al lirismo como remedio contra la generalidad y vacuidad de la abstracción. Esta es en cierta manera una renuncia, una contradicción con la vida, un marginamiento de un pensamiento más original y pleno. Valorizando el papel directo e intransferible de la poesía, desde allí la enfoca hacia un papel que contrasta por ello la vacuidad de un pensamiento generalizado y ajeno a las experiencias vividas y directas.

Al atacar la esclerosis vital de los filósofos modernos, y al compararla con el desenvolvimiento siempre práctico y exento de compromisos burocráticos y de oficio del filósofo antiguo, Cioran asimila la poesía como el único dominio en el que puede rastrearse aún un equivalente con esos modos de vida.

No obstante, guardando las proporciones, un Wilde daría la idea de un Aristipo moderno. En lo referente a Heráclito, Sócrates o Diógenes, es igualmente en el mundo de las letras en donde habría que buscar sus símiles. Más de un poeta moderno podría rivalizar con ellos. La poesía es el único dominio en el que guardamos esta desenvoltura de la vida y del pensamiento, esta inspiración tanto desenfrenada como misteriosa que los antiguos, expertos en el arte de verificar los problemas, aportaron en los debates más abstractos (Cioran, 2009, p. 81). ${ }^{24}$

En el vínculo que une la expresión poética con la experiencia de vida, Cioran destaca la inmediatez con que se desvela una relación que, en la medida de prescindir de una orientación personal, estaría condenada a ser un manifiesto enteramente vacío. El poeta en este caso todavía guardaría la palabra inmediata perdida en la del filósofo profesional, quien como funcionario o profesor, presenta un amplio margen de impersonalidad y esterilidad, en las cuales la ausencia del dramatismo que caracteriza lo auténticamente vivido, sólo puede reconocerse la expresión conceptual vacía y generalizada.

No en vano un espíritu próximo al de Cioran como lo fue María Zambrano, expresa una idea similar:

24 « Cependant, toute proportion gardée, un Wilde donnerait à peu près l'idée d'un Aristippe moderne. Pour ce qui [est] de Héraclite, de Socrate ou de Diogène, c'est également dans le monde de Lettres qu'il faudrait chercher leurs pendants. Plus d'un poète moderne pourrait rivaliser avec eux. C'est que la poésie est le seul domaine où nous ayons gardé cette désinvolture de vie et de pensée, cette inspiration tout ensemble débridée et mystérieuse que les anciens, experts dans l'art de vérifier les problèmes, apportaient dans les débats les plus abstraits ». 
Es que la poesía ha sido en todo tiempo, vivir según la carne. Ha sido el pecado de la carne hecho palabra eternizado en la expresión. (...) El filósofo a la altura en que Platón había llegado, tenía que mirarla con horror, porque era la contradicción del logos (Zambrano, 2006, p. 47).

De manera inversa, en el horror que Cioran tiene por la filosofía, y principalmente, por la académica, por su rigidez y pompa conceptual, se demarca el límite por medio del cual al menos en este caso, la expresión directa de la poesía tiene una aprobación que, si bien tal como se ha visto puede llegar a ser muy fluctuante en Cioran, dependiendo de los periodos y las perspectivas con las cuales la aborda, impregna un sentido u orientación personal que en ningún caso puede marginarse de las exigencias de un pensador signado por el peso de sus obsesiones. De esta manera se puede corroborar por qué las que frecuentemente presenta el autor en sus textos sólo pudieron expresarse a partir de un refinamiento lírico supremo o un intento de ausencia del mismo que en cualquier caso, define su atractivo. La poesía es, concretando toda la ambigüedad cioraniana, una aberración sublime (Cioran, 2011, p. 1773).

\section{Conclusiones}

Los rasgos escriturales que pueden apreciarse en la obra cioraniana están determinados por una muy clara voluntad de estilo. Siempre presente dentro de las exigencias del autor, por ella adoptó no sólo sus propias particularidades estilísticas sino una postura muy crítica por la cual rechazó la tendencia farragosa y oscura de ciertas posturas filosóficas del pasado siglo. Dentro de la pretensión por explicitar una contundente expresión estilística, Cioran concentró dos rasgos fundamentales en relación con los estilos que adoptó en distintas etapas de su labor escritural. El periodo rumano, marcado principalmente por una tendencia muy arraigada hacia la expresión lírica y subjetiva, y un periodo que concuerda con el cambio de lengua al francés, desde el cual adopta un tono más crítico, escéptico y moralista.

Al identificar estos dos periodos o mejor, concentraciones estilísticas, es importante resaltar que ambas definen una pretensión muy arraigada que denota los objetivos de Cioran en torno a la impronta formal que lega en su obra desde dos ópticas. La primera de ellas, de donde surge su tonalidad lírica, como expresión de un enfoque filosófico determinado por una perspectiva trágica en la que el fondo irracional de la existencia intenta expresarse a través de tal expresión. En segunda instancia, la prosa ácida y desencantada, que intenta liberarse de los "éxtasis" líricos, 
procura un encuentro más directo con la perspectiva escéptica que caracteriza a Cioran en no pocas de sus obras. Ambas directrices estilísticas coinciden sin embargo en la necesidad de establecer una conexión directa con una orientación filosófica. La definición del estilo en ambas direcciones concuerda en el primero de los casos con una postura que acoge el fondo irracional que se expresa en medio de los éxtasis líricos, mientras en el segundo, con el desencanto, desengaño y definición escéptica del hombre, se enfoca un tono que intenta concordar con tal especificidad.

Es así como en el autor rumano, la elección estilística está determinada y conectada íntimamente con una perspectiva filosófica, precisando el hecho de identificar por ello forma y contenido de una manera sumamente estrecha y coherente. Ya sea desde los alcances líricos de sus obsesiones trágicas o místicas, así como desde las reservas escépticas que rodean sus dudas en torno a los alcances del hombre, la escritura de Cioran conforma una identidad formal que concuerda con los parámetros de un pensamiento al cual le es imposible definirse al margen de un estilo.

\section{Referencias}

Aristóteles. (1999). Poética. Madrid: Gredos.

Cavaillès, N. (2011). Notice sur Précis de décomposition. En E. Cioran, Euvres (pp. 12991344). Paris: Gallimard.

Chioaru, D. (2015). Le bilinguisme de Cioran. En D. Aurélien, N. Cavaillès, C. Laurent et al. (Eds.), Cioran, archives paradoxales. Nouvelles approches critiques (pp. 125-130). Paris: Classiques Garnier.

Cioran, E. (1997). Cahiers 1957-1972. Paris: Gallimard.

Cioran, E. (2009). Les Cahiers de l'Herne. Paris. Editions de L'Herne.

Cioran, E. (2011). CEuvres. N. Cavaillès y D. Aurélien (Eds.). Paris: Gallimard.

Gajardo Jaña, P. (2018). El lirismo como método de canalización agónica de la irracionalidad de Cioran. Mutatis Mutandis: Revista internacional de filosofia, 10, 75-92.

Izquierdo López, N. (2013). E. M. Cioran. El prestidigitador de la belleza. El rumor del cuerpo en la contradicción de la lengua. $452^{\circ} \mathrm{F}$. Revista electrónica de teoría de la literatura y literatura comparada, 8, 47-60. Disponible en: https://www.452f.com/index.php/natalia-izquierdo/

Nietzsche, F. (1997). El nacimiento de la tragedia. Madrid: Alianza Editorial.

Nietzsche, F. (2008). Fragmentos póstumos 4. Madrid: Tecnos.

Nietzsche, F. (2014). La gaya ciencia. En Obras completas Volumen 3 Obras de madurez. Madrid: Tecnos.

Marín, J. M. (2001). Cioran o el laberinto de la fatalidad. Valencia: Diputació de València. 
Cioran, el escepticismo y la elección estilística

Ricoeur, P. (2004). Tiempo y narración 1. Configuración del tiempo en el relato histórico. México: Siglo XXI.

Rigoni, M. A. (2009). Cioran dans mes souvenirs. Paris: PUB.

Stânisor, M. (2003). Les Cahiers de Cioran, un document poḯtique. En Approches critiques 4. Textes réunis par Eugène Van Itterbeek. Leuven: Editions les Sept dormants.

Valcan, C. (2013). The fascination of artifice. Valéry and Cioran. Procedia - Social and Behavioral Sciences, 71(28), 189-195.

Valcan, C. (2016). Influencias culturales francesas y alemanas en la obra de Cioran (L. Herrera, Trad.). Pereira: Universidad Tecnológica de Pereira.

Zambrano, M. (2006). Filosofía y poesía. México: FCE. 